\title{
Prevalence and Species Spectrum of Pulmonary Nontuberculous Mycobacteria Isolates at a Tertiary Care Center
}

\author{
Young Sun Joo', Na Eun Kwak', Gun Han Kim³, Eun-Jeong Yoon ${ }^{4}$, Seok Hoon Jeong ${ }^{4}$ \\ ${ }^{1}$ Department of Clnical Pathology, Sangji University College of Science, Wonju, ${ }^{2}$ BioPark Diagnostics Inc., \\ ${ }^{3}$ Department of Laboratory Medicine, Gangnam Severance Hospital, ${ }^{4}$ Department of Laboratory Medicine and \\ Research Institute of Bacterial Resistance, Yonsei University College of Medicine, Seoul, Korea
}

\begin{abstract}
Background: Pulmonary infection with nontuberculous mycobacteria (NTM) is increasing in South Korea. Since treatment strategy differs by NTM species, accurate identification is necessary. In this study, using Mycobacterium pulmonary isolates recently recovered from a general hospital in Seoul, the prevalence of NTM isolates was investigated.

Methods: A total of 483 Mycobacterium pulmonary strains isolated between May and November 2018 from an 814-bed general hospital in South Korea were analyzed. Bacterial species were identified based on nucleotide sequences of the 16S-23S rDNA internal transcribed spacer and the rpoB gene. Results: From a total of 1,209 pulmonary specimens from patients suspected to be infected with mycobacteria, 324 deduplicate strains were isolated, comprising 90 Mycobacterium tuberculosis and 229 NTM strains. Among the NTM isolates, $61.5 \% \quad(n=144)$ were Mycobacterium avium complex (MAC), including 92 M. avium and 52 Mycobacterium intracellulare,
\end{abstract}

while $8.1 \% \quad(n=19)$ represented Mycobacterium abscessus, including $10 \mathrm{M}$. abscessus subsp. abscessus and $9 \mathrm{M}$. abscessus subsp. massiliense. In addition, 12 (5.1\%) Mycobacterium lentiflavum, 12 (5.1\%) Mycobacterium gordonae, 6 (2.6\%) Mycobacterium kansasii, and $5(2.1 \%)$ Mycobacterium fortuitum were identified. In addition, Mycobacterium mucogenicum $(n=2)$, Mycobacterium septicum $(n=1)$, Mycobacterium colombiens $(\mathrm{n}=1)$, Mycobacterium asiaticum $(n=1)$, and Mycobacterium celatum $(n=1)$ were identified.

Conclusion: Among the recently recovered Mycobacterium pulmonary strains, more than half were identified as NTM, and MAC was the most prevalent NTM, followed by M. abcessuss. (Ann Clin Microbiol 2019;22:71-76)

Key Words: Non-tuberculosis mycobacteria, Pulmonary specimen, Species identification

\section{INTRODUCTION}

결핵은 결핵균(Mycobacterium tuberculosis, MTB)에 의한 감 염으로 발병하며 전 세계의 공중보건을 크게 위협하는 질환 중 하나이다. 다만 사회경제적 여건 개선에 따라 발병률이 감소추 세이고, 결핵에 의한 사망 또한 줄어들고 있어서, 2000 년에는 $23 \%$ 에 달하던 사망률이 2017년에는 $16 \%$ 로 줄어든 바 있다[1]. 이에 반해 비결핵 항산균(nontuberculous mycobacteria, NTM) 에 의한 호흡기 감염의 비율이 높아지고 있고 면역력이 약화된 사람에게 기회감염의 형태로 빈번히 확인되고 있다[2].

NTM은 Mycobacterium 속의 항산균 중 MTB complex와 나 병균(Mycobacterium leprae)을 제외한 균종을 일컬으며, 토양
과 물에 흔하게 존재하지만[3] 폐질환, 림프절염, 피부 질환, 파 종성 질환 등의 질병을 유발할 수 있고[4], 그 중에서도 폐질환 을 가장 흔히 유발한다[2]. 1943년에 폐결핵이 의심되는 요양 병원 입원환자에서 Mycobacterium avium complex (MAC)에 의한 감염이 처음 보고된 바 있으며[5], 1980년대 이후 지속적 으로 발병 건수가 증가하여 왔다. 미국, 유럽 등 선진국에서 특 히 NTM 감염의 보고가 빈번하고[6], 대한민국 또한, 사회경제 적 여건 개선에 따라 MTB에 의한 폐결핵의 비율이 줄고 NTM 에 의한 폐질환의 비율이 높아지고 있다[7]. 폐질환의 원인균으 로 분리되는 NTM 균종의 분포율은 지역적 차이가 있으나[8], $\mathrm{MAC}$ 이 비교적 가장 흔한 균종인 것으로 보고되고 있고, 그 중 에서도 Mycobacterium intracellulare가 비교적 많이 분리되는

Received 10 April, 2019, Revised 7 May, 2019, Accepted 20 May, 2019

Correspondence: Eun-Jeong Yoon, Department of Laboratory Medicine and Research Institute of Bacterial Resistance, Yonsei University College of Medicine, 211 Eonju-ro, Gangnam-gu, Seoul 06273, Korea. (Tel) 82-2-2019-3783, (Fax) 82-2-2019-3784, (E-mail) ejyoon@yuhs.ac

(c) The Korean Society of Clinical Microbiology.

(ㅈ) This is an Open Access article distributed under the terms of the Creative Commons Attribution Non-Commercial License (http://creativecommons.org/licenses/by-nc/4.0) which permits unrestricted non-commercial use, distribution, and reproduction in any medium, provided the original work is properly cited. 
경향이 있다. 이밖에 Mycobacterium abscessus, Mycobacterium massiliense, Mycobacterium fortuitum, Mycobacterium gordonae, Mycobacterium kansasii, Mycobacterium xenopi 등도 흔하 게 분리되는 것으로 보고된 바 있다[9].

항산균 감염 폐질환이 의심되는 경우, 적절한 약물 치료 전 략을 결정하기 위해 일단 MTB과 NTM을 구분하고, NTM임이 확인되면 추후 정확한 균종을 동정한다. NTM 균종은 핵산 부 합법(nucleic acid hybridization), 지방산 분석법(mycolic acid analysis), 중합효소 연쇄반응물 제한표소 절단법(PCR restriction enzyme analysis), 중합효소 연쇄반응 기반 유전자 염 기서열분석법(PCR-based sequencing analysis) 등의 신속 동정 법을 이용하여 확인하는 것이 일반적이다[10]. 이들 중 가장 간 편하여 빈번하게 이용되는 PCR 산물의 염기서열분석법은 $16 \mathrm{~S}$ rDNA [11], 16S-23S rDNA internally transcribed spacer (ITS) [12], $65 \mathrm{kDa}$ heat-shock protein hsp65 gene [13], RNA polymerase beta-subunit $r p o B$ gene [14] 등의 유전자를 타겟으로 한 다. 이 중 $16 \mathrm{~S} \mathrm{rDNA}$ 는 균종 간 염기서열 유사도가 매우 높아 균종을 정확히 동정하기 힘들고, $h s p 65$ 유전자와 $r p o B$ 유전자 는 정확한 분석을 위해 긴 염기서열을 분석해야 한다는 어려움 이 있어[15], 균종간 염기서열 다양성이 보존된 약 $400 \mathrm{bp}$ 가량 의 $16 \mathrm{~S}-23 \mathrm{~S} \mathrm{rDNA}$ ITS 염기서열 분석이 균종 동정에 자주 사용 된다. 세균의 균종 동정에 자주 적용되고 있는 단백질 질량 분 석법도 이들 항산균 동정에 사용되고 있기는 하나[16], 데이터 베이스가 완전치 않아 사용에 제약이 있다.

본 연구에서는, 3 차 종합병원의 미생물 검사실에 항산균 배 양검사가 의뢰된 호흡기 검체를 대상으로 배양을 시도하여, 분 리 배양한 항산균의 균종을 동정하고, 균종별 분리 빈도를 확 인하고자 하였다.

\section{MATERIALS AND METHODS}

\section{Mycobacteria 분리배양}

2018년 5월에서 11월까지 7개월간 814병상 규모의 서울 소 재 종합병원의 진단검사의학과로 항산균 배양검사가 의뢰된 객담 및 기관지세척액 1,209 검체에 대해 Clinical and Laboratory Standards Institute의 가이드라인에 따라 분리배양을 실시하 였다[17]. 간략히, 검체와 동량의 N-acetyl-L-cysteine-sodium hydroxide- $1.5 \% \mathrm{NaOH}$ 를 첨가한 후 균질화하고, 3,500 rpm에 서 15 분간 원심분리한 후, 침전물을 $3 \%$ Ogawa (Union lab, Seoul, Korea) 고체배지 및 BD Mycobacteria Growth Indicator Tube (BD BBL, Franklin lakes, NJ, USA)에 접종하여, 배양이 관찰될 때까지 6-8주 동안 $37^{\circ} \mathrm{C}$ 에서 배양하였다.

\section{2. 총 유전체 추출}

배양 양성이 확인된 비중복 324주의 배양액 또는 세균 집락 현탁액에 동량의 $4 \% \mathrm{NaOH}$ 를 넣어 진탕하고, 그 중 $1 \mathrm{~mL}$ 를 미 량튜브에 넣어 원심분리하였다. 침전물을 phosphate buffered saline으로 2회 세척하고, 원심분리하여 수확한 침전물에 DNA extraction buffer (Kogen biotech, Seoul, Korea)를 $100 \mu \mathrm{L}$ 첨가 하여 20 분간 꼻였다. $13,500 \mathrm{rpm}$ 에서 5 분간 원심분리하여 얻은 상층액을 $-20^{\circ} \mathrm{C}$ 에서 냉동보관하였다.

\section{PCR 및 염기서열 결정}

본 연구에서 사용한 프라이머는 Table 1에 기술하였다. 16S-23S rDNA ITS는 ITS-F_rrs-1395-1415와 ITS-R_rrl-81-62 프라이머를 사용하여 증폭하였다. 총 $20 \mu \mathrm{L}$ 의 반응액에 추출 된 $2 \mu \mathrm{L}$ 의 총 DNA, 각 $2 \mu \mathrm{L}$ 의 전측 후측 프라이머와 증류수 및 AccuPower PCR premix (Bioneer, Daejon, Korea)가 함유되 도록 하여 $97^{\circ} \mathrm{C}$ 에서 2 분간 predenaturation 후 총 30 회의 $97^{\circ} \mathrm{C}$ denaturation 10 초, $63^{\circ} \mathrm{C}$ annealing 15 초, $72^{\circ} \mathrm{C}$ elongation 30 초 후, $72^{\circ} \mathrm{C}$ 에서 5 분간 최종 elongation 하였다. $1 \%$ 의 아가로스젤 에 전기영동하여 증폭산물의 사이즈를 확인하고 $\mathrm{MG} \mathrm{PCR}$ product purification SV (MGmed, Seoul, Korea)로 정제하여 ITS-F_rrs-1395-1415 프라이머로 염기서열을 결정하였다. $16 \mathrm{~S}-23 \mathrm{~S}$ rDNA ITS 분석을 통해 M. abscessus로 확인된 경우, rpoB_MABS_F2728-2748와 rpoB_MABS_R3078-3056 프라이 머를 사용하여 위와 동일한 조성 및 방법으로 $\mathrm{PCR}$ 하였다. rpoB_MABS_F2728-2748 프라이머로 $r p o B$ 유전자 일부의 염 기서열을 결정하였다.

\section{4. 균종 동정}

$16 \mathrm{~S} \mathrm{rDNA}, 23 \mathrm{~S} \mathrm{rDNA}$ 결정된 약 $450 \mathrm{bp}$ 의 $16 \mathrm{~S}-23 \mathrm{~S} \mathrm{rDNA}$ ITS 염기서열은 내부 데이터베이스와 비교하였다. 내부 데이터 베이스는 species가 확정된 mycobacterial genome의 $16 \mathrm{~S}-23 \mathrm{~S}$

Table 1. Primers used in the study

\begin{tabular}{llcc}
\hline \multicolumn{1}{c}{ Primer } & \multicolumn{1}{c}{ Sequence $\left(5^{\prime}-3^{\prime}\right)$} & Target gene & Tocation $\left({ }^{\circ} \mathrm{C}\right)$ \\
\hline ITS-F_rrs-1395-1415 & CCCGTCACGTCATGAAAGTC & $r r s$ & $1395-1415$ \\
ITS-R_rrl-81-62 & GAGGCWTATCGCAGCCTCC & $r r l$ & $81-62$ \\
rpoB_MABS_F2728-2748 & GACATCATCCTGAACACCCAC & $r p o B$ & $2728-2748$ \\
rpoB_MABS_R3078-3056 & CAGCTTCAGGATGTACATGTAAC & $r p o B$ & 61.6 \\
\hline
\end{tabular}


rDNA ITS 염기서열을 미국의 National Center for Biotechnology Information (NCBI)에서 운영하는 Prokaryotic RefSeq Genome database에서 추출하여 제작하였으며, 총 34종의 Mycobacterium species를 확인할 수 있도록 하였다. 전체 길이 약 $450 \mathrm{bp}$ 중 7 개 미만의 nucleic acid 상이성을 보이는 경우 동일 균종으로 인 정하도록(nucleic acid identity $\geq 98.5 \%$ ) 하였다. 이 과정을 통 해 균종이 동정되지 않거나 non-restricted nucleotide collection database에서 Mycobacterium spp.로 동정된 경우를 Mycobacterium spp.로 분류하였다. M. abscessus의 경우, Mycobacterium abscessus subsp. abscessus, Mycobacterium abscessus subsp. bolletii 및 Mycobacterium abscessus subsp. massiliense의 ITS 염기 서열이 동일하여 아종을 구분하는 것이 불가능하므로[18], $r p o B$ 유전자 일부의 염기서열 약 $200 \mathrm{bp}$ 를 결정하여, $M . a b-$ scessus 3개 아종의 $r p o B$ 유전자 염기서열을 포함하도록 제작 한 내부 데이터베이스와 비교하여 상동성 $\geq 99.5 \%$ 을 기준으로 결정하였다.

\section{RESULTS}

\section{1. 배양 양성 균주 중 MTB과 NTM}

7 개월의 연구 기간 중 항산균 배양검사가 의뢰된 총 1,209 객담 및 기관지세척액 검체 중 324 (26.8\%) 검체에서 비중복 mycobacteria 균주를 분리하였다. 배양액 또는 배양된 집락에 서 추출한 총 유전체에 대해여 $16 \mathrm{~S}-23 \mathrm{~S}$ rDNA ITS의 염기서열 분석을 실시한 결과, 전체의 $1 / 3$ 에 해당하는 균주 $(27.8 \%, 90 / 324)$ 가 MTB였고, 2/3에 해당하는 균주(72.2\%, 229/324)가 NTM으 로 확인되었다.

\section{NTM 균종 분포}

$\mathrm{NTM}$ 으로 확인된 229예 중, 과반(61.5\%, $\mathrm{n}=144)$ 이 $\mathrm{MAC}$ 에 속하는 균종으로 확인되었으며, 그 중 약 2/3 (92/144, 63.9\%) 는 M. avium, 1/3 (n=52, 36.1\%)은 M. intracellulare로 동정되었 다. 차순위로, 19 예(8.1\%)가 M. abscessus로 확인되었고, 그 중 절반(n=10)은 M. abscessus subsp. abscessus, 나머지 절반(n=9) 은 M. abscessus subsp. massiliense로 확인되었다. 또한 Mycobacterium lentiflavum 12예(5.1\%), Mycobacterium gordonae 12 예(5.1\%), M. kansasii 6예(2.6\%) 및 M. fortuitum 5예(2.1\%)가 확인되었다. 산발적으로, Mycobacterium yongonense $(\mathrm{n}=2)$, Mycobacterium mucogenicum ( $\mathrm{n}=2)$, Mycobacterium septicum $(\mathrm{n}=1)$, Mycobacterium colombiens $(\mathrm{n}=1)$, Mycobacterium asiaticum $(\mathrm{n}=1)$, Mycobacterium celatum $(\mathrm{n}=1)$, Mycobacterium chimaera $(\mathrm{n}=1)$ 가 확인되었고, 나머지 27예는 균종을 특정할 수 없는 Mycobacterium spp.이었다(Table 2).
Table 2. Mycobacterial isolates identified in this study

\begin{tabular}{lr}
\hline \multicolumn{1}{c}{ Species } & Number of strain (proportion) \\
\hline Total & 324 \\
M. tuberculosis & $90(27.8 \%)$ \\
Non-tuberculosis Mycobacteria & $234(72.2 \%)$ \\
M. avium complex & $144(61.5 \%)$ \\
$\quad$ M. avium & $92(63.9 \%$ of MAC) \\
$\quad$ M. intracellulare & $52(36.1 \%$ of MAC) \\
M. abscessus & $19(8.1 \%)$ \\
subsp. abscessus & $10(52.6 \%$ of M. abscessus) \\
subsp. massiliense & $9(47.4 \%$ of M. abscessus) \\
M. lentiflavum & $12(5.1 \%)$ \\
M. gordonae & $12(5.1 \%)$ \\
M. kansasii & $6(2.6 \%)$ \\
M. fortuitum & $5(2.1 \%)$ \\
M. yongonense & $2(0.9 \%)$ \\
M. mucogenicum & $2(0.9 \%)$ \\
M. septicum & $1(0.4 \%)$ \\
M. colombiens & $1(0.4 \%)$ \\
M. asiaticum & $1(0.4 \%)$ \\
M. celatum & $1(0.4 \%)$ \\
M. chimaera & $1(0.4 \%)$ \\
Mycobacterium spp. & $27(11.5 \%)$ \\
\hline
\end{tabular}

\section{DISCUSSION}

약 7개월에 걸친 항산성균 유래 폐질환에 대한 원인균 분리 동정을 통해 임상, 검체에서 $\mathrm{MTB}$ 와 NTM이 $1: 2.5$ 의 비율로 분리됨을 확인하였고, $16 \mathrm{~S}-23 \mathrm{~S}$ rDNA ITS 분석 후 $M . a b$ $s c e s s u s$ 에 대한 $r p o B$ 유전자를 분석하는 2단계의 NTM 균종 동 정 알고리즘을 이용하여 $70 \%$ 가량의 NTM이 MAC 또는 $M . a b-$ scessus에 속함을 확인하였다. 7개월의 짧은 기간동안 수집된 검체를 이용한 것이고, 서울 소재 한 개 종합병원에서의 결과 를 분석한 내용이므로 해당 분석결과가 국내 전체를 대표하는 결과라 할 수 없다는 한계가 있으나, 국내에서 분리된 항산성 균에 대한 최신의 감시 결과로써 기존의 감시 결과의 흐름과 일맥상통하는 분리율을 확인할 수 있었다.

2009년부터 2016년까지 우리나라에서 확인된 NTM 유병률 은 2009년 10만 명당 9.4명에서 매년 증가하여 2016년에는 10 만 명당 36.1명으로 증가하였다는 보고가 있다[19]. MTB와 $\mathrm{NTM}$ 의 분리 비율은 국내에서도 지역적 차이를 확인할 수 있 는데, 2001년부터 2011년까지 10년간 서울 소재 3차 의료기관 에서 실시한 항산성균 호흡기감염 의심 검체 분석결과에 따르 면, 2001년에 67\% : 43\%이던 MTB와 NTM의 비율이 2005년 에 $48 \%$ : 52\%로 역전되었고, 2011년에는 30\%: $70 \%$ 로 NTM 에 의한 호흡기 감염이 MTB에 의한 호흡기 감염을 크게 웃돌 게 되었음이 확인되었다[20]. 경남 울산지역의 3차 의료기관에 서 실시한 연구에서는, 2011 년에 $75 \%: 25 \%$ 이던 MTB와 NTM 
의 비율이 2013 년에 $62 \%$ : $38 \%$ 가 되어, 비율의 역전은 아직 확인되지 아니하였으나, NTM의 비중이 점차 높아지는 양상을 확인한 바 있다[21]. 본 연구에서는 MTB와 NTM의 비율이 $31.1 \%$ : $68.9 \%$ 로 확인되어 2011 년의 서울지역의 분석결과와 다르지 아니함이 확인되었다. MTB에 의한 결핵에 비해 NTM 에 의한 폐질환의 비율이 높아지고 있는 양상은 미국[22], 캐나 다[23], 호주[24] 및 일본을 포함한 동아시아[25]와 비슷하게 관 찰되고 있다.

최근 연구에서 국내에서 호흡기감염을 일으키는 NTM 중 $\mathrm{MAC}$ 이 가장 흔하며, 이 중 M. intracellulare가 M. avium보다 빈도가 더 높은 것으로 보고되었다[8]. 본 연구에서도 NTM으 로 확인된 229개 균주 중, 과반에 해당하는 균주(61.5\%)가 $\mathrm{MAC}$ 으로 확인되었다. 다만, 이들의 보고와 다르게 M. avium 이 M. intracellulare보다 약 1.8 배 더 많이 분리되는 양상을 보 였다. 서울 소재 3차 의료기관의 최신 보고에 따르면 M. avium 과 M. intracellulare의 분리 비율은 2001년에 30\%: $70 \%$ 였던 것이 2015년에는 54\% : 46\%로 변했다고 하며[26], 본 연구의 결과가 이러한 경향을 반영하는 것으로 생각한다. 국내에서 두 번째로 흔한 호흡기 감염 원인균으로 M. abscessus subsp. $a b$ scessus 가 지목된 것은 본 연구뿐 아니라 최근의 다른 보고에서 도 마찬가지였다[8,27]. 다만, M. abscessus subsp. abscessus의 분리빈도는 국가간 큰 차이가 있어, 최근 일본 오키나와 중부 에 위치한 550병상 규모의 병원에서는 M. abcessus가 NTM 양 성 호흡기 검체의 $1 / 3$ 에 육박하여 M. intracellulare보다도 1.5 배 가량 빈번하게 검출되는 것으로 보고된 바 있다[28]. M. $a b$ scessus 의 subsp.간 비율은 M. abscessus subsp. abscessus와 $M$. abscessus subsp. massiliense이 동일하여, 2017년에 발표된 국 내 감시 결과와 일치하였다[29]. 미국과 일본에서 흔하게 발견 되는 것으로 보고되고 있는 M. kansasii [9]는, 이번 연구에서는 $\mathrm{NTM}$ 중 $2 \%$ 도 채 차지하지 못하는 것으로 확인되었고, 이는 2010년의 국내 보고와 일치하는 결과였다[30]. 더불어, M. lentiflavum, M. gordonae를 포함하는 환경유래 균의 경우, 분리 비 율 자체에 대한 의미를 부여하기보다 실제 감염과 연개된 경우 인지에 대해 추적관찰을 할 필요가 있다.

$\mathrm{NTM}$ 으로 인한 폐질환은 전 세계적으로 급격한 증가 추세를 보이고 있으며 균종별 치료전략이 매우 다르기 때문에 빠르고 정확한 균종 동정이 필요하다. 본 연구를 통해 폐질환의 원인 균 중 $\mathrm{MTB}$ 에 비해 NTM의 분리 비율이 높다는 사실을 확인하 였고, NTM 균종을 정확히 구분할 수 있는 알고리즘을 개발하 여 균종을 확인하였다. NTM을 구성하는 균종의 비율은 동일 한 지역에서 실시한 최근의 감시 결과와 큰 차이가 없어 변화 의 속도가 매우 빠르지는 않은 것으로 파악되나, 자연내성으로 인해 치료가 특히 힘들어 악명을 떨치고 있는 M. absecuss subsp. abscessus와 NTM 유래 폐질환의 흔한 원인균인 MAC 의 두 아종 중 M. avium subsp. avium이 subsp. intracellulare보
다 흔하게 분리되는 현 상황을 주목해 지켜보아야 할 필요가 있다.

\section{REFERENCES}

1. WHO. Global tuberculosis report 2018. Geneva: WHO; 2018.

2. Griffith DE, Aksamit T, Brown-Elliott BA, Catanzaro A, Daley C, Gordin F, et al. An official ATS/IDSA statement: diagnosis, treatment, and prevention of nontuberculous mycobacterial diseases. Am J Respir Crit Care Med 2007;175:367-416.

3. Wolinsky E. Nontuberculous mycobacteria and associated diseases. Am Rev Respir Dis 1979;119:107-59.

4. Primm TP, Lucero CA, Falkinham JO 3rd. Health impacts of environmental mycobacteria. Clin Microbiol Rev 2004;17:98-106.

5. Feldman WH, Davies R, Moses HE, Andberg W. An unusual mycobacterium isolated from sputum of a man suffering from pulmonary disease of long duration. Am Rev Tuberc 1943;48: 272-90.

6. Diagnosis and treatment of disease caused by nontuberculous mycobacteria. This official statement of the American Thoracic Society was approved by the Board of Directors, March 1997. Medical Section of the American Lung Association. Am J Respir Crit Care Med 1997;156(2 Pt 2):S1-25.

7. Go WJ, Kwon OJ, Yu CM, Jeon KM, Seo JY, Jeong MP, et al. Recovery rate of nontuberculous mycobacteria from acid-fast-bacilli smear-positive sputum specimens. Tuberc Respir Dis 2003;54: 22-32.

8. Hoefsloot W, van Ingen J, Andrejak C, Angeby K, Bauriaud R, Bemer $\mathrm{P}$, et al. The geographic diversity of nontuberculous mycobacteria isolated from pulmonary samples: an NTM-NET collaborative study. Eur Respir J 2013;42:1604-13.

9. Kwon YS and Koh WJ. Diagnosis and treatment of nontuberculous mycobacterial lung disease. J Korean Med Sci 2016;31: 649-59.

10. Shin S, Kim EC, Yoon JH. Identification of nontuberculous mycobacteria by sequence analysis of the $16 \mathrm{~S}$ ribosomal RNA, the heat-shock protein 65 and the RNA polymerase beta-subunit genes. Korean J Lab Med 2006;26:153-60.

11. Turenne CY, Tschetter L, Wolfe J, Kabani A. Necessity of quality-controlled 16S rRNA gene sequence databases: identifying nontuberculous Mycobacterium species. J Clin Microbiol 2001;39: 3637-48.

12. Roth A, Fischer M, Hamid ME, Michalke S, Ludwig W, Mauch H. Differentiation of phylogenetically related slowly growing mycobacteria based on 16S-23S rRNA gene internal transcribed spacer sequences. J Clin Microbiol 1998;36:139-47.

13. Kim H, Kim SH, Shim TS, Kim MN, Bai GH, Park YG, et al. Differentiation of Mycobacterium species by analysis of the heat-shock protein 65 gene (hsp65). Int J Syst Evol Microbiol 2005;55(Pt 4):1649-56.

14. Kim BJ, Lee SH, Lyu MA, Kim SJ, Bai GH, Chae GT, et al. Identification of mycobacterial species by comparative sequence analysis of the RNA polymerase gene $(r p o B)$. J Clin Microbiol 1999;37:1714-20.

15. Adékambi T, Colson P, Drancourt M. $r p o B$-based identification of nonpigmented and late-pigmenting rapidly growing mycobacteria. J Clin Microbiol 2003;41:5699-708.

16. Alcaide F, Amlerová J, Bou G, Ceyssens PJ, Coll P, Corcoran D, et al; European Study Group on Genomics and Molecular 
Diagnosis (ESGMD). How to: identify non-tuberculous Mycobacterium species using MALDI-TOF mass spectrometry. Clin Microbiol Infect 2018;24:599-603.

17. CLSI. Laboratory detection and identification of mycobacteria M48. CLSI document M48-A. Wayne, PA: Clinical and Laboratory Standards Institute; 2018.

18. Tortoli E, Kohl TA, Brown-Elliott BA, Trovato A, Leão SC, Garcia MJ, et al. Emended description of Mycobacterium abscessus, Mycobacterium abscessus subsp. abscessus and Mycobacteriumabscessus subsp. bolletii and designation of Mycobacteriumabscessus subsp. massiliense comb. nov. Int J Syst Evol Microbiol 2016;66:4471-9.

19. Yoon HJ, Choi HY, Ki M. Nontuberculosis mycobacterial infections at a specialized tuberculosis treatment centre in the Republic of Korea. BMC Infect Dis 2017;17:432.

20. Koh WJ, Chang B, Jeong BH, Jeon K, Kim SY, Lee NY, et al. Increasing recovery of nontuberculous mycobacteria from respiratory specimens over a 10-year period in a tertiary referral hospital in South Korea. Tuberc Respir Dis (Seoul) 2013;75:199-204.

21. Lee MY, Lee T, Kim MH, Byun SS, Ko MK, Hong JM, et al. Regional differences of nontuberculous mycobacteria species in Ulsan, Korea. J Thorac Dis 2014;6:965-70.

22. Adjemian J, Olivier KN, Seitz AE, Holland SM, Prevots DR. Prevalence of nontuberculous mycobacterial lung disease in U.S. Medicare beneficiaries. Am J Respir Crit Care Med 2012;185: 881-6.

23. Marras TK, Mendelson D, Marchand-Austin A, May K, Jamieson FB. Pulmonary nontuberculous mycobacterial disease, Ontario, Canada, 1998-2010. Emerg Infect Dis 2013;19:1889-91.
24. Thomson RM; NTM working group at Queensland TB Control Centre and Queensland Mycobacterial Reference Laboratory. Changing epidemiology of pulmonary nontuberculous mycobacteria infections. Emerg Infect Dis 2010;16:1576-83.

25. Ide S, Nakamura S, Yamamoto Y, Kohno Y, Fukuda Y, Ikeda H, et al. Epidemiology and clinical features of pulmonary nontuberculous mycobacteriosis in Nagasaki, Japan. PLoS One 2015;10: e0128304.

26. Ko RE, Moon SM, Ahn S, Jhun BW, Jeon K, Kwon OJ, et al. Changing epidemiology of nontuberculous mycobacterial lung diseases in a tertiary referral hospital in Korea between 2001 and 2015. J Korean Med Sci 2018;33:e65.

27. Kim SY, Kim CK, Bae IK, Jeong SH, Yim JJ, Jung JY, et al. The drug susceptibility profile and inducible resistance to macrolides of Mycobacterium abscessus and Mycobacterium massiliense in Korea. Diagn Microbiol Infect Dis 2015;81:107-11.

28. Nagano H, Kinjo T, Nei Y, Yamashiro S, Fujita J, Kishaba T. Causative species of nontuberculous mycobacterial lung disease and comparative investigation on clinical features of Mycobacterium abscessus complex disease: a retrospective analysis for two major hospitals in a subtropical region of Japan. PLoS One 2017;12:e0186826.

29. Koh WJ, Jeong BH, Kim SY, Jeon K, Park KU, Jhun BW, et al. Mycobacterial characteristics and treatment outcomes in Mycobacterium abscessus lung disease. Clin Infect Dis 2017;64:309-16.

30. Park HK, Koh WJ, Shim TS, Kwon OJ. Clinical characteristics and treatment outcomes of Mycobacterium kansasii lung disease in Korea. Yonsei Med J 2010;51:552-6. 
$=$ 국문초록 $=$

\section{호흡기 검체에서의 비결핵 항산균 분리율}

${ }^{1}$ 상지대학교 임상병리학과, ${ }^{2}$ 바이오파크진단 주식회사, ${ }^{3}$ 강남세브란스병원 진단검사의학과,

${ }^{4}$ 연세대학교 의과대학 진단검사의학교실 및 세균내성연구소

주영선 ${ }^{1}$, 곽나은 $^{2}$, 김건한 $^{3}$, 윤은정 $^{4}$, 정석훈 $^{4}$

배경: 비결핵 항산균(nontuberculous mycobacteria, NTM)은 균종에 따라 치료 전략이 상이하므로 신속하고 정확한 균종의 동정과 균종별 분리율에 대한 동향 파악이 필요하다. 본 연구에서는 호흡기 임상검체에서 분리한 NTM의 균종별 분리율 을 조사하였다.

방법: 2018년 5월에서 11월까지 7개월간 서울 소재 814병상 규모 종합병원의 진단검사의학과로 배양검사가 의뢰된 항산 균 감염 의심 환자의 객담 및 기관지세척액 1,209 검체에서 균주를 분리배양하여 추출한 DNA를 대상으로 $16 \mathrm{~S}-23 \mathrm{~S} \mathrm{rDNA}$ internal transcribed spacer 및 $r p o B$ 유전자를 증폭하여 분석한 염기서열 기반으로 균종을 동정하였다.

결과: 총 1,209 검체의 배양검사 결과 분리된 483 예 중 $31.1 \%(n=150)$ 는 결핵균이었고, $68.9 \%(n=333)$ 는 NTM이었다. 이들 NTM 중, 67.6\% (225/333)가 Mycobacterium avium complex이었으며, M. avium 137예와 Mycobacterium intracellulare 88예로 구성되어 있었다. NTM 중 9.0\%는 Mycobacterium abscessus (30/333)였으며, M. abscessus subsp. abscessus (n=15)와 M. abscessus subsp. marsiellense ( $\mathrm{n}=15)$ 로 구성되어 있었다. 또한 Mycobacterium lentiflavum 13예(3.9\%), Mycobacterium gordonae 12예(3.6\%), Mycobacterium fortuitum 6예(1.8\%) 및 Mycobacterium kansasii 6예(1.8\%)가 확인되었다. 이밖에, Mycobacterium yongonense, Mycobacterium mucogenicum, Mycobacterium septicum, Mycobacterium colombiens, Mycobacterium asiaticum, Mycobacterium celatum 및 Mycobacterium chimaera 균주가 1-2예씩 확인되었다.

결론: NTM에 의한 폐질환은 항산균 감염 중 $2 / 3$ 으로 그 비율이 높아지고 있어 NTM 분리 균종과 분리빈도에 대한 지속 적 관리와 감시가 필요하며, 특히 자연내성으로 치료에 어려움을 겪는 M. abscessus subsp. abscessus의 분리율이 5\%에 육박하는 바, 이에 대한 지속적 관찰이 요구된다. [Ann Clin Microbiol 2019;22:71-76]

교신저자 : 윤은정, 06273 , 서울시 강남구 언주로 211

연세대학교 의과대학 진단검사의학교실 및 세균내성연구소

Tel: 02-2019-3783, Fax: 02-2019-3784

E-mail: ejyoon@yuhs.ac 